\title{
Research on Investment Efficiency of Environmental Protection Resources of Chemical Enterprises Based on Audit Information
}

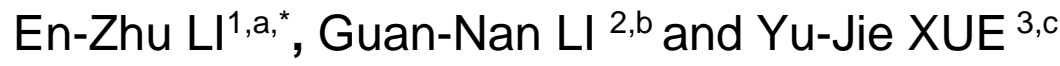 \\ ${ }^{1}$ School of Accounting, Shandong University of Finance \& Economics, Jinan 250014, China \\ ${ }^{2}$ Shandong Company of Kaiyuan Securities Co., Ltd, Ji'nan 250014, China \\ 3 Ji'nan Company of Sunac China Holdings Limited, Ji'nan 250101, China \\ aemail: lez11513@163.com, bemail: Ign0785@163.com, cemail: xueyujie2011@163.com \\ ${ }^{*}$ Corresponding author
}

\begin{abstract}
Keywords: Auditing, Efficiency of Resources, Environmental Protection, Chemical enterprises.
Abstract. There are many environmental pollution factors in the production process of chemical enterprises. Environmental protection is a prerequisite for normal production in the entire chemical industry, and a large amount of resources should be put into environmental protection for preventing environmental pollution accidents. This paper systematically discusses the requirements of application for the introducing audit data to efficiency assessment system of environmental protection resources. meanwhile, the characteristics of recommended methed of DEA are also explained. This DEA method of efficiency assessment can be applied to all units of a chemical enterprise which may cause environmental pollution accidents in chemical production, and is also used to estimate and reflect the efficiency of resource invested to prevent environmental pollution accidents. Based on the function of this evaluation system, the main framework of data envelopment analysis (DEA) of efficiency evaluation system which is consistent with the characteristics of audit data of chemical enterprises is proposed. The purpose of this study is to help effectively manage the resources invested in environmental protection based on information of auditing.
\end{abstract}

\section{Introduction}

In the entire production process of chemical companies, all kinds of substances discharged into the environment exceed a certain limit, which will cause the deterioration of environmental ecological quality. Not only that, but the discharge of these emissions from various chemical companies can also cause direct human injury or deterioration of health conditions[1]. These chemical plant emissions include dust, industrial wastewater and various exhaust gases such as sulfur dioxide and nitrogen oxides[2]. Chemical companies have been included in China's high environmental pollution industry. It turns out that many science and technology should work together to solve environmental pollution problems in chemical production. Many Chinese and world scholars have put forward their research opinions on environmental protection from many angles[3]. These theories play an important role in the environmental protection of various units and enterprises, especially chemical companies. An excellent environment suitable for human survival is the basis for the sustainable development of chemical industry production and human society, and also a symbolic representative of social civilization and progress. At present, the problem of environmental degradation has become more and more serious and has become a problem that China must face. In order to achieve environmental protection goals, it is necessary to construct an efficiency evaluation system that rationally evaluates the resources for ecological protection inputs. Therefore, this paper will briefly discuss the advanced methods of resource efficiency assessment based on audit information.

\section{Necessity of Establishing System of Evaluating Efficiency}

\section{Requirements for Sustainable Development of Chemical Industry}

In 1992, the World Commission on Environment and Development (WCED) officially established sustainable development. Sustainability means meeting the development of current needs without 
compromising the ability of future generations to meet their needs. People are the main body of social survival and development. People's needs include all aspects, including the excellent natural environment[4]. In sustainable development, not only economic growth, but also resources, the environment, social progress and overall human development are also indicators for evaluating sustainable development. Similar to all things, no environmental pollution accidents in chemical production are the most basic guarantee for enterprises to obtain maximum return. Therefore, investing in environmental protection resources is the most important investment in producing chemical products and creating profits, and is also the basic requirement for sustainable development of chemical industry.

\section{Enlargement of Application of Auditing Data}

The purpose of the audit work is to ensure the normal operation of the daily production activities of the enterprise and the stable operation of the financial management system of the enterprise. The current highly developed technology and high-speed growth of the social economy have gradually expanded the functions of audit work. Audit data can play an important role in more and more areas, and audit information now serves many objects. Under the guidance of auditing theory, systematically studying the application of audit data in the environmental resource efficiency evaluation system will be a new field of audit research.

\section{Requirement of Enlargement of Environmental-protection Resources}

In the era of knowledge economy, people have a strong dependence on the excellent ecological environment, and there is an urgent need for investment in ecological protection. Personal health threats and huge economic losses caused by environmental pollution accidents have made people pay more attention to the economic significance of environmental protection. When paying attention to the meaning of life and health, attention should be paid to social benefits and economic losses. Insufficient environmental investment in chemical companies, the instability of chemical raw materials, and poor management of chemical companies will greatly increase the possibility of environmental pollution accidents. Environmental pollution accidents not only affect the normal production of chemical companies, but also cause serious health damage to workers and residents. It is necessary to establish a long-term environmental protection mechanism in such enterprises, establish a financial management and economic evaluation system for investing resources, and safeguard the interests of chemical enterprises, employees and the public. Environmental protection investment resources, especially environmental protection funds, are special resources for improving the ecological production conditions of chemical enterprises. Environmental protection funds should be allocated according to fixed standards on a regular basis, included in the normal production costs of chemical enterprises and used according to environmental protection needs. Whether it is allocation, inclusion of cost or use should be subject to supervision of audit work.

\section{Explanation of Economic Efficiency in Resources of Environmental Protection}

Although the resources provided by chemical companies for environmental protection have increased significantly in recent years, information provided by domestic and international organizations indicates that environmental pollution accidents remain a major problem due to unsuccessful investment in these resources. Such accidents have also caused great harm to the economy and sustainable development. The "smog incident" is a manifestation of the inefficient efficiency of China's environmental protection resource investment. In January 2017, four smog processes enveloped 30 provinces (autonomous regions and municipalities). As of the end of 2017, Shanghai, Nanjing and other central regions of China suffered the most serious disaster areas. Shanghai has repeatedly seen PM2.5 indices exceeding 500. It is reported that less than 1\% of China's 500 largest cities meet the World Health Organization's recommended air quality standards. At the same time, 7 of the 10 most polluted cities in the world are in China. With the improvement of the living standards of the Chinese people, people's demand for an excellent environment is also increasing. Therefore, the situation of high-frequency accidents of environmental pollution has seriously affected the development of various industries, especially Chinese chemical enterprises, which are the important foundation of China's national economic and social development. Therefore, 
this industry must continue and develop healthily. Environmental protection is the ultimate guarantee for the stable, sustained and rapid development of the chemical industry.

\section{Requirements of Forming Evaluation System}

\section{Refined Mode of Audit Report}

The detailed report form of audit information is completely different from the traditional audit report. In order to make full use of environmental protection resources, it is the goal of capital market audit to maximize the quality and efficiency of resource utilization. The goal of building an environmental protection resource economic benefit evaluation system also puts higher requirements on the form of audit reports. Audit reports related to environmental protection resources should be true, accurate, timely, convenient, applicable and practical. The detailed audit report should not only reflect the actual environmental protection situation of the chemical industry, but also achieve the purpose of predicting the future. The improved audit report should provide not only internal information, but also relevant external information. There should also be monetary information and non-monetary information. The audit report is the "work product" of the audit work. The monotonous model of the audit report should be changed, and the detailed environmental protection resources should be disclosed in the audit report to meet the needs of economic benefit evaluation.

\section{Setting the Related Standards of Auditing}

The audit data used by the efficiency evaluation system is information about the work of environmental protection resources in these enterprises. The following principles should be noted when publishing audit reports in environmental protection resources. First, the amount of relevant audit information in the report should be at least stipulated by the relevant national auditing standards. Secondly, a proprietary audit mechanism for auditing environmental protection resources of chemical companies should be established. Third, the audit information of environmental protection resources and the actual environmental protection effects should be combined. On the other hand, the status quo and utilization efficiency of environmental protection resources can also be provided through a special "Environmental Protection Resources Audit Report".

\section{Main Framework of the Proposed Method}

\section{Outline of Evaluation Method}

Due to the fluctuation of economic benefits and the lack of transparency of environmental protection resource information, it is necessary to analyze the rationality of environmental protection resource supply of chemical enterprises. In order to study the influence of various factors of the above environmental protection resource evaluation system, data envelopment analysis (DEA) method in operational research will be proposed to evaluate the economic benefits of environmental protection resources invested in chemical enterprises [5]. The basic unit of data envelopment analysis is the decision unit (DMU). DEA is a system or activity that can transfer a range of resource input factors or environmental resource assessment factors to a series of decision outputs. Data Envelopment Analysis (DEA) evaluates the decision making unit (DMU) by using a mathematical programming pattern that compares the relative efficiencies between DMUs. Because it evaluates the DMU from the best angle and does not require any obvious relationship between input and output, it is very objective. The necessary data for the DEA method comes from the carefully selected financial data in the audit work. Figure 1 shows the DEA evaluation flow chart for this evaluation.

\section{Formation of the DEA Model for Evaluation}

The efficiency of a Decision-Making Units of DEA, the weighted-value variable of input factors of auditing information of environmental-protection resources and the weighted-value variable of output for decision are separately represented by $z^{t}, v^{t}$ and $u_{j}^{t}$ in a decision-making unit (suppose to $t$ ). The following $C^{2}{ }_{R}$ model of mathematical programming can calculate those three decision variables, as in model (4). There are $N$ decision-making units for evaluating the environmental-protection resources invested in this model (4) of mathematical programming. There are $I$ kinds of input factors 
of auditing date and $J$ kinds of outputs in every decision-making unit. According to modern auditing theory and the needs of evaluate risks, the main input factors of model (4) should contain the auditing data of the total amount of $P E$ (expenses accrued for environmental-protection purpose in a certain period ), the total amount of $P A$ (environmental-protection assets), $T A$ (total assets) and so on.

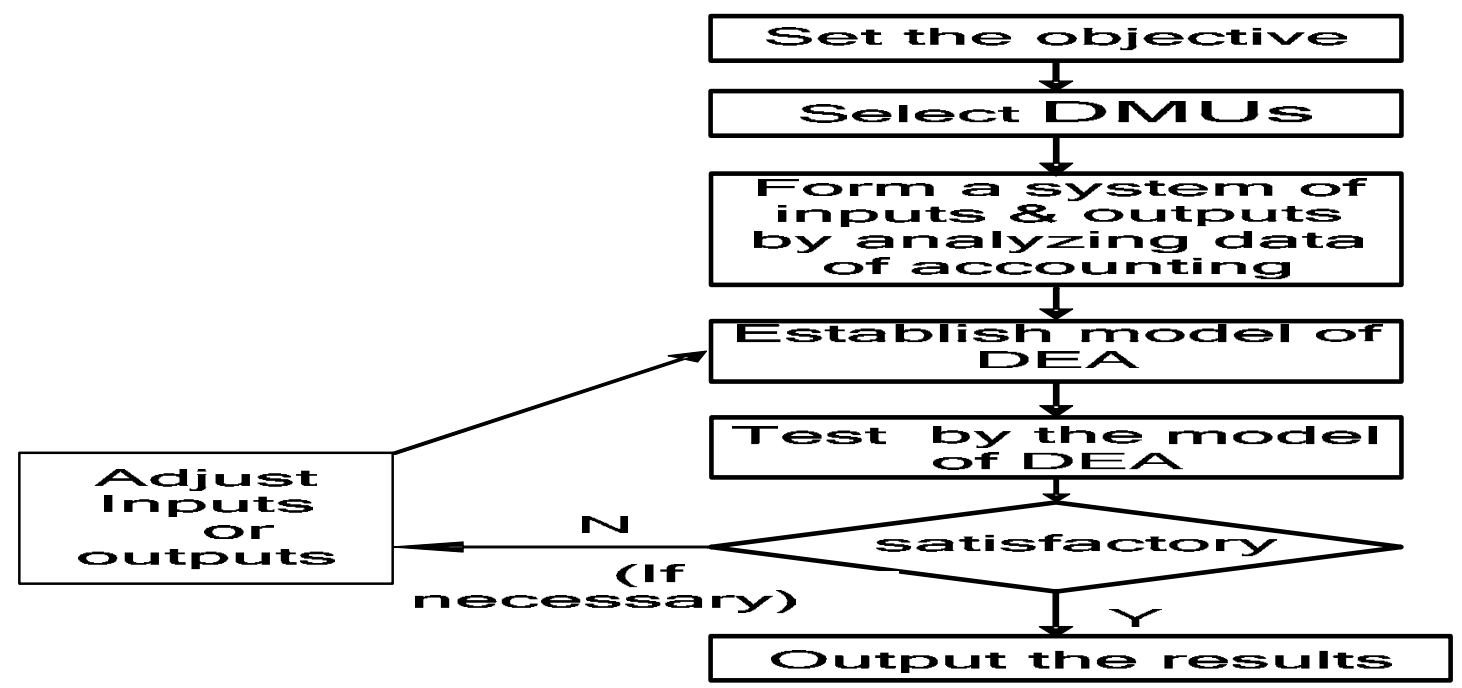

Fig. 1 Flow chart of DEA for evaluation system

The main output factors of model (4) should be the sum of $A L$ (environmental-pollution accident losses in chemical production), $R R A$ (rate of return on environmental-protection assets), $E R$ (equity ratio) and so on, which deal with the firm's profitability. In audit, a Balance Sheet, an Income Statement or other financial reports of the chemical enterprises should be analyzed or investigated to obtain the $P E, C A P, F A P, T A$ and $A L$. The $P A$ includes the sum of $C A P$ (current assets for environmental-protection purpose) and the sum of $F A P$ (fixed assets for environmental-protection purpose), the $P A, R R A$ and $E R$ can be calculated by the following supplementary models of (1), (2) and (3) from the auditing data of financial reports of the chemical enterprises.

$$
\begin{aligned}
& P A=\sum C A P+\sum F A P \\
& R R A=\frac{I_{O}}{\left(T A_{b}+T A_{e}\right) / 2} \\
& E R=\frac{O E_{e}}{T A_{e}}
\end{aligned}
$$

In these models of (1), (2) and (3):

$\sum C A P$ : Sum of current assets for environmental-protection purpose

$\sum F A P$ : Sum of fixed assets for environmental-protection purpose

$T A_{b}$ : Total assets at beginning of the certain period

$T A_{e}$ : Total assets at end of the certain period

$I_{O}$ : Operating Income (Income before interest expense and income tax)

$O E_{e}$ : Owner's Equity (period-end balance)

In the next model of (4), $x^{n}{ }_{i} 、 y_{j}^{n}$ means the No. $i$ input and No.j output in No. $n$ unit, $v^{t}{ }_{i}$, and $u_{j}^{t}$ are the weights of the No. $i$ input factor of evaluating the environmental-protection resources invested and No.j output calculated by the model (4) 


$$
\begin{cases}\max z^{t}=\sum_{j=1}^{J} u_{j}^{t} y_{j}^{t} \\ \text { s.t. } \quad \sum_{i=1}^{I} v_{i}^{t} y_{i}^{t}=1 ; \\ \quad \sum_{j=1}^{J} u_{j}^{t} y_{j}^{n}-\sum_{i=1}^{I} v_{i}^{t} x_{i}^{n} \leq 0 ; \\ n=1, \ldots, t, \ldots, N ; u_{j}^{t} \geq e ; v_{i}^{t} \geq e ; i=1, \ldots, I ; j=1, \ldots, J . .\end{cases}
$$

The $e$ is infinitesimal and the code of unit of environmental-protection resources evaluated to ensure positive weight of all inputs and outputs. This model (4) meets thus a stipulation condition that no a unit of environmental-protection resources evaluated will more than $100 \%$ efficiencies or more than 1.0 ratios when coefficient of the same set of inputs and outputs is used to contrast with all other units. If the different $t$ values are put into this model (4) of mathematical programming, the $z^{t}\left(0<z^{t} \leq 1\right)$, efficiency of a Decision-Making Units of DEA, will be calculated, $z^{t}=1$ means that this decision-making units for evaluating the environmental-protection resources invested in the chemical enterprises is effective and also means lower risks, $z^{t}<1$ means that this decision-making units is inefficiency for the safety resources invested in this chemical enterprises also means higher risks. With the model (4) of $C^{2} R$, the availability of environmental-protection resources supplied in every chemical enterprises can be evaluated on the basis of auditing input data and output data in one of the chemical enterprises, and the range of economic risks of environmental-protection resources invested in the chemical enterprises also be confirmed.

\section{Summary}

If there are enough environmental resources to effectively invest in chemical companies for environmentally friendly production, a win-win result will be formed. The investment in environmental resources is very important for the operation of chemical companies, because if the process efficiency can be improved, it can greatly save costs and reduce environmental pollution accidents. The purpose of this paper is simply to provide new directions for the innovative research on the economic efficiency of environmental resources by means of the characteristics of auditing and related audit data, and to help relevant units make correct environmental protection decisions based on economic efficiency.

\section{References}

[1] Shi Jingang; Zhang Mingbo; Li Dong; Liu Jia: A method to determine the protection zone of chemical industrial park considering air quality, health risk and environmental risk: a case study, Environmental geochemistry and health, Vol. 40, Issue 2 (2018), p. 915-922

[2] Congmei $\mathrm{Fu}, \mathrm{Fu}$ Wang: Environmental Protection and Waste Management of Chemical Enterprises (in Chinese ) , Shandong Chemical Industry, Vol. 46, Issue 20 (2017), p. 181-182

[3] Xinlong Xu; Xiaonan Yang; Liang Zhan; Cheng Kun Liu; Nidi Zhou; Meimei Hu: Examining the relationship between intellectual capital and performance of listed environmental protection companies, Environmental Progress \& Sustainable Energy, Vol. 36, Issue 4 (2017), p. 1056-1066

[4] WANG Chao: Environmental protection measures for coal-fired power plant (in Chinese ), Shanxi Chemical Industry, Vol. 37, Issue 3 (2017), p. 138-139

[5] WANG Xi-Ping: Research on total factor energy efficiency of coal-fired power plant based on super-efficiency DEA (in Chinese ), Power Demand Side Management, Vol. 16, Issue 3 (2014), p. $18-23$ 